\title{
Digital Security, Web Trends \& IEEE Ethernet Alliance
}

Moderator: Oripide Cilento Filho

Engineering Manager / Information and Coordination Center of pontoBR / NIC.br

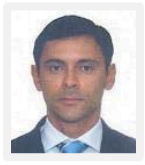

Digital security: Basic concepts and vulnerabilities of loT the Internet of Things

Speaker: George Almeida

Consulting Systems Engineer - Security Sales / Cisco Systems

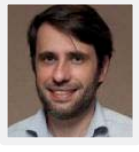

HTML5 applications for interaction with Digital TV

Speaker: Reinaldo Ferraz

Web Development Specialist / W3C Brazil

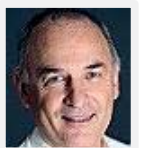

The next generation of high-speed networks

Speaker: Oripide Cilento Filho

Engineering Manager / Information and Coordination Center of pontoBR / NIC.br

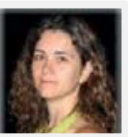

Security on the Internet: trends and challenges Speaker: Miriam Von Zuben

Senior Security Analyst / CERT.br/NIC.br

Digital Content - Security and Protection over DTHs and IP Networks: Piracy, Risks, Mitigation, Prevention and

Solutions

Speaker: Gabriel Ricardo Hahmann

Sales Director, Brazil and Southern Cone / Irdeto 


\title{
Internet \& TV
}

\section{DIGITAL SECURITY, WEB TRENDS \& IEEE ETHERNET ALLIANCE}

\author{
Moderator: Oripide Cilento Filho \\ Engineering Manager / Information and Coordination Center of pontoBR / NIC.br
}

This Session aims to cover issues surrounding the future of the Internet and TV, given digital convergence. Thus, the presentations will aim to demonstrate how to cope with the challenges of the years ahead: risks in IoT, Web applications and TV, challenges in high-speed networks, security on the Internet and Protection of Content in a variety of forms on networks (VoD/IP/DTH).

- Digital security: Basic concepts and vulnerabilities of loT - the Internet of Things

Speaker: George Almeida

Consulting Systems Engineer - Security Sales / Cisco Systems

This presentation will expose the risks and possible approaches to mitigation with the reality that will be the world of interconnected things in the not-too-distant future.

- HTML5 applications for interaction with Digital TV Speaker: Reinaldo Ferraz Web Development Specialist / W3C Brazil

The purpose is to present the key resources that HTML5 offers for extending interactivity and communication using the Digital TV interface. Web applications and synchronized subtitles, multiple screens and real-time communication, among other things.

- The next generation of high-speed networks

\section{Speaker: Oripide Cilento Filho}

Engineering Manager / Information and Coordination Center of pontoBR / NIC.br

Deals with the Roadmap of the new trends in transmission rates and trends in fiber and metal cable networks. Update about Ethernet technology beyond 1G (5G, $10 \mathrm{G}, 25 \mathrm{G}, 100 \mathrm{G}, 400 \mathrm{G}$ in fiber and UTP), aspects of how to use this.

\section{- Security on the Internet: trends and challenges}

\section{Speaker: Miriam Von Zuben}

Senior Security Analyst / CERT.br/NIC.br

Recent years have seen a quantum change in the internet security scenario, with massive exposure of sensitive data and critical infrastructures, the increasing financial motivation behind the attacks and the increasing number of interconnected items of equipment. This talk will deal with several aspects of the most frequent attacks reported to CERT.br; what the main trends are and what challenges users and security professionals will have to face if the overall scenario is to improve. 
- Digital Content - Security and Protection over DTHs and IP Networks: Piracy, Risks, Mitigation, Prevention and Solutions

Speaker: Gabriel Ricardo Hahmann

Sales Director, Brazil and Southern Cone / Irdeto

Presentation aims to discuss digital content protection over different networks.
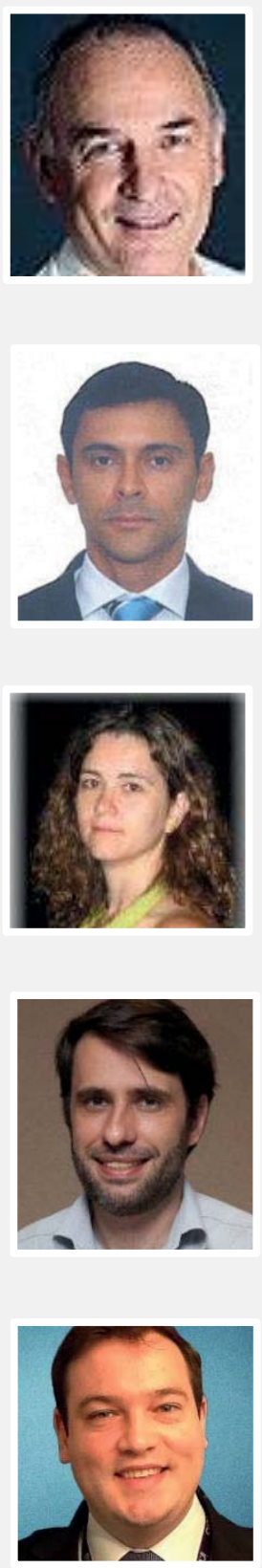

\section{ORIPIDE CILENTO FILHO}

Engineering Manager - Information and Coordination Center of Ponto BR / NIC.br Oripide Cilento Filho, holds an electrical engineering degree from FEI (1981) and a graduate degree in Digital TV Transmission Systems from INATEL (2005). He is the Engineering Manager for the Information and Coordination Center of Ponto BR (NIC.br), having been Technical Director at the USP Computation Center, Operations and Engineering Manager of news agency, Agencia Estado, and engineer at TV Globo - São Paulo and a university professor on Electrical Engineering and Computer Network Courses.

\section{GEORGE ALMEIDA}

Consulting Systems Engineer - Security Sales / Cisco Systems

Unicamp-educated Electrical Engineer, with a graduate degree in business management from Ibmec-SP/Insper, CCIE R\&S certified, with over 18 years' experience among manufacturers, providers and integrators in the fields of telecommunications, networks and security. At Cisco since 2012, he is currently a sales consultant for network security solutions.

\section{MIRIAM VON ZUBEN}

Senior Security Analyst - CERT.br/NIC.br

Miriam von Zuben is a Senior Security Analyst at do CERT.br/NIC.br, and handles User Training and Awareness. Gives talks and develops material involving good security practices. She is also a course instructor at the CERT/CC, of the Carnegie Mellon University. She is the main supporter of the Internet Security Guidebook.

\section{REINALDO FERRAZ}

Specialist in development web - W3C Brazil

Holds a degree in design and computer graphics, and a graduate degree in hypermedia design from the Anhembi Morumbi University in São Paulo. He has worked for over 14 years in web development. Coordinator of projects involving the Open Web Platform and Web accessibility. He is the representative of W3C Brazil at technical plenary sessions of the W3C.

\section{GABRIEL RICARDO HAHMANN}

Sales Director, Brazil and Southern Cone / Irdeto Working in the telecommunications and digital TV industry for more than 12 years and over 4 years at Irdeto, Gabriel Hahmann has been part of the development of one of the first IPTV deployments in Latin America as part of the Telefonica Group.Gabriel has a diploma in Engineering, with strong security background with an academic training in Information Security at IBTA and several vendor certifications in ITIL, Linux, Oracle, Cisco and F5. Gabriel joined Irdeto in 2012 to lead the Pre Sales Engineering area for Latin America, moving to Sales in 2015 to take care of Brazil and Colombia markets.

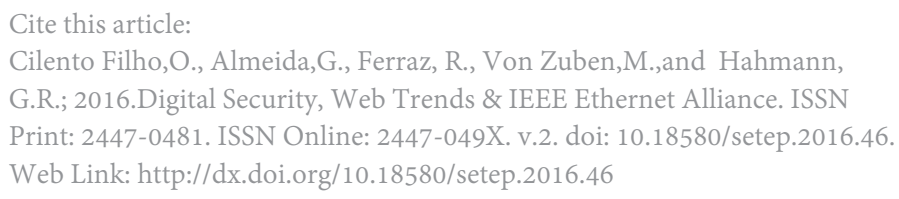

